\title{
A School Survey on Use and Knowledge of Apps and Websites for Promoting Mental Wellbeing
}

\author{
Andrea Taylor \\ The Glasgow School of Art \\ Moray, UK \\ A.Taylor@gsa.ac.uk
}

\begin{abstract}
Mental wellbeing is the combination of feeling good and functioning well. Digital technology widens the opportunities for promoting mental wellbeing, particularly among those young people for whom technology is an ordinary part of life. This paper presents the findings of a school survey on apps and websites that have a primary purpose of promoting mental wellbeing, involving 308 young people (12-16 years) and 86 staff from seven schools across a region of Scotland, UK. Nearly half of the young respondents displayed a lack of understanding of mental wellbeing or misunderstood mental wellbeing as mental health problems, and a very few reported using an app or website with a primary purpose of promoting mental wellbeing. The main contribution to $\mathrm{HCl}$ is identifying a problem area in need of further exploration: how to improve the use and knowledge of good quality apps and websites for promoting mental wellbeing among young people aged 12-18 years.
\end{abstract}

Mental health; mental wellbeing; young people; digital technology; survey.

\section{INTRODUCTION}

Mental health is a leading global public health challenge (World Health Organization, 2013). Achieving good mental health requires the complementary activities of promoting mental wellbeing and preventing and treating mental health problems (Keyes, 2014). This study is concerned with promoting mental wellbeing. Mental wellbeing is the combination of feeling good and functioning well: feeling good incorporates the positive emotions of happiness, contentment, interest, engagement, confidence and affection; functioning well involves the development of one's potential, having some control over one's life, having a sense of purpose and experiencing positive relationships (Huppert, 2009). A range of factors influence our level of mental wellbeing including genetic, environmental and socio-cultural factors, and life events. However, evidence indicates that our actions may have a greater influence (Aked et al., 2008). It is therefore important to explore ways to support individuals to promote their mental wellbeing.

Digital technology widens the opportunities for promoting mental wellbeing, particularly among those young people for whom technology is an ordinary part of life. For example, in the UK, almost all 12-24 year olds (98\%) go online, and the majority of 12-15 year olds (79\%) and 16-24 year olds
(93\%) use a smartphone (Ofcom, 2016, 2017). This study explores an area that is particularly under researched: young people's use and knowledge of apps/websites that have a primary purpose of promoting mental wellbeing. The research was conducted within the context of a school setting, given the increasing emphasis on mental health promotion within schools across the UK over recent years (e.g. Mental Health Taskforce, 2016; Scottish Government, 2017). For example, in Scotland, where this research was conducted, Health and Wellbeing is a core part of the national curriculum for schools (Education Scotland, n.d.). This paper contributes to the body of research within $\mathrm{HCl}$ on design for mental wellbeing. The main contribution is identification of a problem area in need of further exploration: how to improve the use and knowledge of good quality apps/websites with a primary purpose of promoting mental wellbeing among young people aged $12-18$ years.

\section{METHOD}

An online survey titled 'Apps and Websites for Promoting Mental Wellbeing' was distributed to 10 secondary schools (ages: 12-18 years) across a region of Scotland, UK. The survey had two versions: one for young people and one for school staff. The questions are listed below. 


\subsection{Young People Survey}

1. What school do you attend?

2. How old are you?

3. In your own words, what does mental wellbeing mean to you?

4. *Which apps or websites have you used to promote (improve) your mental wellbeing?

5. How did you find out about these apps and/or websites?

6. How would you rate your knowledge about apps and websites for promoting mental wellbeing?

* Respondents were asked to skip to question 6 if they have never used an app or website to promote their mental wellbeing.

\subsection{School Staff Survey}

1. What school do you work at?

2. What is your role?

3. *Which apps or websites for promoting (improving) mental wellbeing have you recommended to young people at your school?

4. How did you find out about these apps and/or websites?

5. How would you rate your knowledge about apps and websites for promoting mental wellbeing?

* Respondents were asked to skip to question 5 if they have never recommended an app or website for promoting mental wellbeing.

\section{RESULTS}

\subsection{Young People Survey}

Three hundred and eight young people from six schools participated in the survey, aged 12-16 years, with the age breakdown as follows: 12 years (48 respondents), 13 years (64 respondents), 14 years (124 respondents), 15 years (61 respondents) and 16 years (11 respondents).

\subsubsection{Q3: In your own words, what does mental wellbeing mean to you?}

A comment box was provided to collect open-ended responses. The responses were organised into the following nine themes, listed in order of size: lack of understanding, emotions, mind, mental health problems, coping, stability, healthy lifestyle, World Health Organization (WHO) definition, and safety.

\section{Lack of Understanding}

Thirty-one respondents described mental wellbeing in terms of what the phrase implies e.g. 'the wellbeing of your mentality'. Twenty-five respondents wrote a form of 'I don't know'. Twenty- three respondents wrote comments that suggested a total lack of understanding e.g. 'I don't have it' and 'it means how strong your brain is and how well you can read and write'. Seven respondents wrote that mental wellbeing is important but did not elaborate.

\section{Emotions}

Thirty-four respondents described mental wellbeing in terms of happiness e.g. 'being happy and not having depression' and 'if you're happy with yourself and are happy with your life in general'. A further 16 respondents referred to other positive emotions e.g. 'feeling positive about yourself, life and people around you' and 'having a good body image and thinking positive thoughts about yourself'. Twentythree respondents more broadly described mental wellbeing in terms of emotions e.g. 'it's like how is your mood today, how do $u$ feel and stuff like that' and 'it means that you have a good mental mind set, and you know how to process different emotions'.

\section{Mind}

Fifty-six respondents described mental wellbeing in terms of the state and/or health of an individual's mind e.g. 'mental wellbeing is ur state of mind'. A few of these respondents commented on ways to keep the mind healthy e.g. 'it's the way you care for your brain for example sleeping and eating'. Twelve respondents more broadly described mental wellbeing in terms of an individual's mind e.g. 'it is to do with your mind'.

\section{Mental Health Problems}

Twenty-nine respondents described mental wellbeing in terms of the presence of mental health problems e.g. 'this means an illness in your head like depression and anxiety' and 'mental wellbeing means that you have a disorder such as anger management or you are depressed'. Conversely, 14 respondents described mental wellbeing in terms of the absence of mental health problems e.g. 'it means your brain works normal and you got no depresssions' and 'the fact that one is not mentally insane makes them mentally well'.

\section{Coping and Stability}

Fourteen respondents described mental wellbeing in terms of coping e.g. 'it means people can cope with the stresses of life and different things that challenge them'. Nine respondents described mental wellbeing in terms of stability e.g. 'when you're mentally stable' and 'mental wellbeing means how stable you are and how well you can cope with situations'.

\section{Healthy Lifestyle, WHO Definition and Safety}

Eight respondents described mental wellbeing in terms of a healthy lifestyle e.g. 'mental wellbeing means that you are healthy and active'. Four respondents referenced the WHO definition of mental health, which is: 'a state of well-being in which every individual realizes his or her own potential, can cope with the normal stresses of life, 
can work productively and fruitfully, and is able to make a contribution to her or his community' (World Health Organization, 2014). Finally, three respondents described mental wellbeing in terms of safety e.g. 'mental wellbeing means that you are safe in yourself and you don't feel insecure'.

\subsubsection{Q4: Which apps and websites have you used} to promote (improve) your mental wellbeing?

A comment box was provided to collect openended responses. Forty respondents answered this question. Ten respondents wrote the name of a specific app/website that has a primary purpose of promoting mental wellbeing: Breathe, Childline, Health, NHS Choices, SAMH (Scottish Association for Mental Health) and Silent Secret (later rebranded to Cypher). Two of these apps/websites are directly targeted at young people: Childline and Silent Secret. Twenty respondents named an app/website not obviously connected with mental wellbeing, although possibly beneficial e.g. Instagram and Clash of Clans (game). The remaining 10 respondents named a website focused on mental health problems e.g. Depression Chat Rooms and Moodjuice.

\subsubsection{Q5: How did you find out about these apps and/or websites?}

Respondents could select multiple answers from a defined list of choices, as follows. Forty respondents answered this question. Fifteen respondents chose 'Guidance teacher at your school' (Guidance teachers deliver personal and social education [PSE]); 10 chose 'Friend at your school'; 8 chose 'Internet search engine e.g. Google'; 4 chose 'Apple iTunes or Google Play store'; none chose 'Other adult at your school' or 'School nurse at your school'; and 10 chose 'Other'. The responses for 'Other' were categorized as 'other adults e.g. parents' and 'other technologies e.g. YouTube'.

\subsubsection{Q6: How would you rate your knowledge about apps and websites for promoting mental wellbeing?}

Respondents could select one answer from a defined list of choices: 'High', 'Moderate' and 'Low'. Half (154) of respondents chose 'Low'; 133 chose 'Moderate'; and 21 chose 'High'. However, in light of how those respondents who chose 'High' answered Q3 'What does mental wellbeing mean to you?' it is likely that they all overrated their knowledge. For example, one respondent wrote 'it means do not smoke' for Q3, displaying a lack of understanding of mental wellbeing, thereby casting doubt on their choice of 'High' for Q6.

\subsection{School Staff Survey}

In Scotland, all school staff are responsible for pupils' learning in mental, emotional, social and physical wellbeing. Eighty-six staff from seven schools participated in the survey. Nearly half of respondents (49\%) were teachers. The remaining respondents incorporated: support staff e.g. administrator, janitor and home school link worker; pupil support assistants; and senior staff e.g. depute head and head of department.

\subsubsection{Q3: Which apps or websites for promoting (improving) mental wellbeing have you} recommended to young people at your school? A comment box was provided to collect openended responses. Seventeen respondents answered this question. Ten respondents wrote the name of a specific app(s)/website(s) that has a primary purpose of promoting mental wellbeing: Change4Life, Childline, Couch to $5 K$, Headspace, Mindspace, SAHM, Samaritans, Smiling Mind and YoungMinds. Three of these apps/websites are directly targeted at young people: Childline, Smiling Mind and YoungMinds. Five of these respondents, plus seven other respondents, also wrote/wrote the name of 14 apps/websites that are either: primarily focused on mental health problems e.g. MoodGYM; tackling mental health discrimination e.g. See Me; or are only tangentially related to mental health e.g. Crossreach (charity that provides social care services to vulnerable populations).

\subsubsection{Q4: How did you find out about these apps and/or websites?}

Respondents could select multiple answers from a defined list of choices, as follows. Seventeen respondents answered this question. Five respondents selected 'Internet search engine'; two selected 'The Rowan Centre' (the Child and Adolescent Mental Health Service in our area); one selected 'Apple iTunes or Google Play store'; and nine selected 'Other'. The responses for 'Other' were categorized as 'conferences and professional development events', 'colleagues and other associates' and 'lesson planning'.

\subsubsection{Q5: How would you rate your knowledge about apps and websites that can support young people aged 12-18 years to promote their mental wellbeing?}

Respondents could select one answer from a defined list of choices: 'High', 'Moderate' and 'Low'. Sixty-three respondents chose 'Low'; 21 chose 'Moderate'; and two chose 'High'.

\section{DISCUSSION}

\subsection{Key Findings}

\subsubsection{Concept of Mental Wellbeing}

The survey identified a range of interpretations of 'mental wellbeing' among the young respondents; the two biggest themes were lack of understanding and emotions such as happiness. This is consistent with a critical review of the literature on children 
and young people's views of mental health conducted in 2008 (Shucksmith et al., 2009). The review found that children and young people's definitions of mental wellbeing focused on themes of being happy and feeling good about themselves, although younger people (12-14 years) were less clear about what is meant by mental wellbeing. However, the review was limited by the paucity of the literature at the time it was conducted. This study enhances the review by providing recent insights into what mental wellbeing means to young people (12-16 years), in light of the increasing emphasis on mental health promotion within schools across the UK. In particular, the survey finding that nearly half (42\%) of the young respondents displayed a lack of understanding of mental wellbeing or misunderstood mental wellbeing as mental health problems is striking.

\subsubsection{Use and Knowledge of Apps and Websites}

An implication of the survey findings on how young people understand 'mental wellbeing' is that despite growing evidence that digital technologies can be used to improve mental health among young people (e.g. Bidargaddi et al., 2017; Simons et. al., 2015), a problem may exist as to finding those resources that are likely to be helpful-due to lack of understanding or misconceptions about mental wellbeing. This is evident in the survey finding that of the 40 young respondents who stated that they have used an app/website to promote their mental wellbeing, the majority $(75 \%)$ named an app/website not obviously connected with mental wellbeing or primarily focused on mental health problems. I.e. a mismatch was identified between what respondents think they are using and what they are actually using. Digital technologies, e.g. online social networks, can be both advantageous and harmful for mental wellbeing (Best et al., 2014). It is especially important therefore that young people are guided towards good quality resources that are likely to be helpful.

The majority (38\%) of young respondents who reported having used an app/website to promote their mental wellbeing reported finding it through their school staff. However, most (73\%) school staff who responded to the survey rated their knowledge of such apps/websites as 'Low'. Indeed, only seventeen (20\%) school staff respondents reported having recommended an app(s)/website(s) for promoting mental wellbeing, and more than half of the apps/websites they named are either primarily focused on mental health problems, tackling mental health discrimination or tangentially related to mental health. An implication is that some school staff may also have a limited understanding of mental wellbeing. This is consistent with a recent large-scale survey of over 3,000 school staff in Scotland, which found that $66 \%$ of respondents do not feel they have received sufficient training in mental health (SAMH, 2017).

\subsection{Area of Opportunity for $\mathrm{HCl}$ Research}

While a limitation of the study is that the survey was conducted in a single region of Scotland, the survey findings suggest a problem area in need of further exploration: how to improve the use and knowledge of good quality apps/websites for promoting mental wellbeing among young people aged 12-18 years. Other research has also identified that good quality mental health resources are not reaching older young people aged 18-25 years at acceptably high levels (Neal et al., 2011), and the Children's Commissioner for England has noted that while there are some good websites for mental health, it is a 'matter of luck' whether children find them (Richardson, 2015). The numbers are too small to draw conclusions, however, around a third of the young respondents (30\%) and a third of the school staff respondents (35\%) who reported that they have used or recommended an app/website for promoting mental wellbeing found it through an Internet search engine or app store. Consequently, one possible direction for exploration, for which there is currently very limited research on, is: how young people (1218 years) and adults who work to support the learning of young people, understand mental wellbeing (which this study contributes to), and how this is reflected in the terms and phrases (language) that they use when searching online for apps/websites. Health promotion recognises that initiatives are unlikely to be successful unless people's own understandings are taken into account (Secker et al., 1999). A better understanding of these factors could potentially be a useful starting point to improve the use and knowledge of apps/websites for promoting mental wellbeing.

\section{CONCLUSION}

Mental health is a global public health challenge. There is a growing body of evidence that digital technologies such as apps and websites can be used to support young people to promote their mental wellbeing. However, nearly half of the young respondents in this study displayed a poor understanding of mental wellbeing and a very few reported using an app/website with a primary purpose of promoting mental wellbeing. The main contribution of this study is identification of a problem area in need of further exploration: how to improve the use and knowledge of good quality apps/websites with a primary purpose of promoting mental wellbeing among young people aged 12-18 years.

\section{ACKNOWLEDGEMENTS}

Thank you to all those who were involved for their time and support, with special thanks to Susan Leslie. 


\section{REFERENCES}

Aked, J., Marks N., Cordon, C. \& Thompson, S. (2008) Five ways to wellbeing: the evidence. http://neweconomics.org/2008/10/five-ways-towellbeing-the-evidence/ (retrieved $20 \mathrm{Mar}, 2018$ ).

Best, P., Manktelow, R. \& Taylor, B. (2014) Online communication, social media and adolescent wellbeing: A systematic narrative review. Children and Youth Services Review, 41, 27-36.

Bidargaddi, N., Musiat, P., Winsall, M., Vogl, G., Blake, V., Quinn, S., Orlowski, S., Antezana, G. \& Schrader, G. (2017) Efficacy of a web-based guided recommendation service for a curated list of readily available mental health and well-being mobile apps for young people: Randomized controlled trial. J Med Internet Res 19(5):e141.

Education Scotland. What is Curriculum for Excellence? https://education.gov.scot/scottisheducation-system/policy-for-scottish-

education/policy-drivers/cfe-(building-from-the-

statement-appendix-incl-btc1-

5)/What\%20is\%20Curriculum\%20for\%20Excellen ce? (retrieved 28 Mar, 2018).

Huppert, F. (2009) Psychological well-being: Evidence regarding its causes and consequences. Applied Psychology: Health and Well-Being 1, 2: 137-164.

Keyes, C. (2014) Mental health as a complete state: how the salutogenic perspective completes the picture. In: Bauer, G.F. \& Hämmig, O. (eds). Bridging occupational, organizational and public health. Springer Netherlands. 179-192.

Mental Health Taskforce. (2016) The five year forward view for mental health. https://www.england.nhs.uk/wpcontent/uploads/2016/02/Mental-Health-

Taskforce-FYFV-final.pdf (retrieved 28 Mar, 2018).

Neal, D., Campbell, A., Williams, L., Liu, Y. \& Nussbaumer, D. (2011) "I did not realize so many options are available": cognitive authority, emerging adults, and e-mental health. Library and Information Science Research, 33 (1).

New Economics Foundation. (2008) Five ways to wellbeing: the evidence. http://neweconomics.org/2008/10/five-ways-towellbeing-the-evidence/ (retrieved 28 Mar, 2018).

NHS Health Scotland. (2009) A critical review of the literature on children and young people's views of the factors that influence their mental health. http://www.healthscotland.com/documents/3678.a spx (retrieved 28 Mar, 2018).

NHS Health Scotland. (2010) Mental health improvement terminology and working understandings. http://www.healthscotland.com/documents/4614.a spx (retrieved 28 Mar, 2018).

Ofcom. (2017) Adults' media use and attitudes. https://www.ofcom.org.uk/_data/assets/pdf file/0 020/102755/adults-media-use-attitudes-2017.pdf (retrieved 20 Mar, 2018).

Ofcom. (2016) Children and parents: media use and attitudes report. https://www.ofcom.org.uk/_data/assets/pdf_file/0 034/93976/Children-Parents-Media-Use-

Attitudes-Report-2016.pdf (retrieved 20 Mar, 2018).

Richardson, H. (2015) Children seeking mental health advice on internet. http://www.bbc.co.uk/news/education-34423949 (retrieved 28 Mar, 2018).

SAMH. Survey on school staff training in mental health. $\quad$ https://www.samh.org.uk/getinvolved/going-to-be/well-trained (retrieved 31 May, 2018)

Scottish Government. (2017) Mental Health Strategy 2017-2027.

http://www.gov.scot/Publications/2017/03/1750/do wnloads (retrieved $28 \mathrm{Mar}, 2018$ ).

Secker, J., Armstrong, C. \& Hill, M. (1999) Young people's understanding of mental illness. Health Education Research 14 (6): 729-39.

Shucksmith, J., Spratt, J., Philip, K. \& Mcnaughton, R. (2009). A critical review of the literature on children and young people's views of the factors that influence their mental health. http://www.healthscotland.com/documents/3678.a spx (retrieved May 31, 2018).

Simons, L., Craven, M. \& Martin, J. (2015) Learning from the labs volume 2: Evaluating effectiveness, lessons and reflections. http://www.innovationlabs.org.uk/wpcontent/uploads/2015/04/Learning-from-the-LabsVolume-2-Evaluating-Effectiveness.pdf (retrieved 28 Mar, 2018).

World Health Organization. (2013) Mental health action plan 2013-2020. http://www.who.int/mental_health/publications/acti on_plan/en/ (retrieved $28 \bar{M}$ ar, 2018).

World Health Organization. (2014) Mental health: a state of well-being. http://www.who.int/features/factfiles/mental_health /en/ (retrieved 28 Mar, 2018). 